\title{
Evaluation of Hydraulic Performance of Irrigation Scheme at Kuraz Sugar Development Project, Jinka, Ethiopia
}

\author{
Tamene Mojira ${ }^{1}$, Samuel Dagalo ${ }^{2}$ \\ ${ }^{1}$ Civil and Irrigation Engineering Department, Omo Kuraz Sugar Project, Jinka, Ethiopia \\ ${ }^{2}$ Arba Minch Institute of Technology, Department of Water Resource and Irrigation Engineering, Arba Minch, Ethiopia \\ Email address: \\ tmojira7@gmail.com (T. Mojira), samueldagalo@gmail.com (S. Dagalo)

\section{To cite this article:} \\ Tamene Mojira, Samuel Dagalo. Evaluation of Hydraulic Performance of Irrigation Scheme at Kuraz Sugar Development Project, Jinka, \\ Ethiopia. American Journal of Mechanics and Applications. Vol. 9, No. 2, 2021, pp. 18-29. doi: 10.11648/j.ajma.20210902.12
}

Received: October 14, 2021; Accepted: November 1, 2021; Published: November 17, 2021

\begin{abstract}
Performance assessment of irrigation system is important to conserve the scarce resource of water through improving performance of existing irrigation schemes. However, there was no study in the past on performance assessment of Kuraz Irrigation Scheme. Thus, this study was to evaluate the hydraulic performance of the irrigation scheme using hydraulic performance indicators. The study was carried out during the irrigation season from June to August, 2019. According to the results of the study, the value of adequacy, dependability, equity, equity ratio over head to tail, efficiency and deficiency were found to be $0.98,0.03,0.04,0.91,0.81$ and 0.02 respectively. The values show that water delivery system of the scheme had a good performance. The conveyance system was satisfied $98 \%$ out of the total required amount of irrigation water during study period. The overall efficiency of the system was $81 \%$, which implies that the efficiency of water supply was satisfactory. The overall average value of conveyance efficiency of the $3.33 \mathrm{~km}$ Secondary canal was $81.20 \%$. The conveyance loss was $18.80 \%$ of the water. Siltation and vegetation growth within the canal interferes with water flow reducing the conveyance efficiency. The values of effectiveness of infrastructure, water surface elevation ratio, delivery duration ratio and sustainability of irrigated areas were found to be $89.68 \%, 96 \%, 87.5 \%$ and $95.56 \%$ respectively. The results of maintenance indicators showed that the system requires minimum level of maintenance due to sedimentation of secondary canal, improper operation and management of the system. Hence, adequate maintenance and other proper management techniques are essential to improve the irrigation system performance.
\end{abstract}

Keywords: Hydraulic Performance, Water Utility Indicator, Conveyance Efficiency, Maintenance Indicators, 90 Degree V-Notch, Kuraz Irrigation Scheme

\section{Introduction}

Water scarcity is a growing worldwide problem challenging sustainable development and placing a constraint on producing enough food to meet increasing food requirements [1]. Water scarcity is a potential constraint to produce more foods to meet the demands of increasing world population. One possible approach to conserve this scarce resource might be through improving the performance of existing irrigation schemes [2]. Performance based management is a principal approach to improve the scheme performances.

Nowadays majority of operational irrigation schemes in the Ethiopia are characterized by a poor level of technical, hydraulic, operational and service delivery performance.
Shortcomings include inadequate irrigation scheduling, inadequate operation plan, water logging and salinization, lack of adequate institutional setups for management, inadequate physical water control facilities, canal sedimentation and lack of adequate maintenance, lack of appropriate asset management [3].

Irrigation development is a key for sustainable agricultural development which leads to overall development in Ethiopia [4]. Irrigation schemes are classified as small, medium and large-scale depending on the size of the command area [5]. Based on irrigation scheme classification small-scale irrigation scheme is defined as the area less than 200 ha; which are often community-based and traditional methods. Ethiopian irrigation scheme classification, medium scale irrigation scheme is covering 200 to 3,000 ha which is 
community based or publicly sponsored.. According to Ministry of Water Resources, large scale is covering more than 3,000 hectares, which is typically commercially or publicly [6].

Secondary canal was designed by Water Works Design Construction Supervision Enterprise in 2011. It was constructed by Ethiopian Water Works Construction Enterprise in 2014. The secondary canal, SC-4 is off taking at $17.135 \mathrm{klometers}$ of the main canal on left bank. The secondary has a length of 3.33 kilometers to irrigate a net irrigable area of 777.5 ha and it has 10 off-taking tertiary canals. A total of 35 quaternary offtakes from tertiary canals supply irrigation water to the fields. The design discharge of the secondary canal- 4 is 1.33 cubic meter and the bed width of the canal varies from $1.70 \mathrm{~m}$ to $0.60 \mathrm{~m}$. There are 46 head regulating and 40 cross regulating structures in both secondary and tertiary canals to regulating the flow the system. The canals are constructed as an open channel excavated \& shaped to the required cross section in natural earth or compacted fills [7]. Secondary canal four on left bank of Omo Kuraz irrigation scheme, some of irrigation structures which were malfunctioned due to different reasons such as unreliable water deliveries, poor control and distribution system, lack of proper management, improper operation of water delivery system, delivery of excess water which causes canal bed scouring and sedimentation, improper operating of hydraulic gates, weed growth and flooding problems. The water delivery performance of the canals, the delivery of a fair share of water to the reaches, and the level of maintenance requirement of the system is not clearly understood. Hence, assessing the hydraulic performance of the schemes has now become a paramount importance to point out where the problem lies, and to identify alternatives for effective and feasible improvement of irrigation system performance. So far, specifically in the study area there is no any assessment done regarding hydraulic performance. Therefore, the aim of this study was to evaluate the hydraulic performance of Kuraz irrigation scheme.

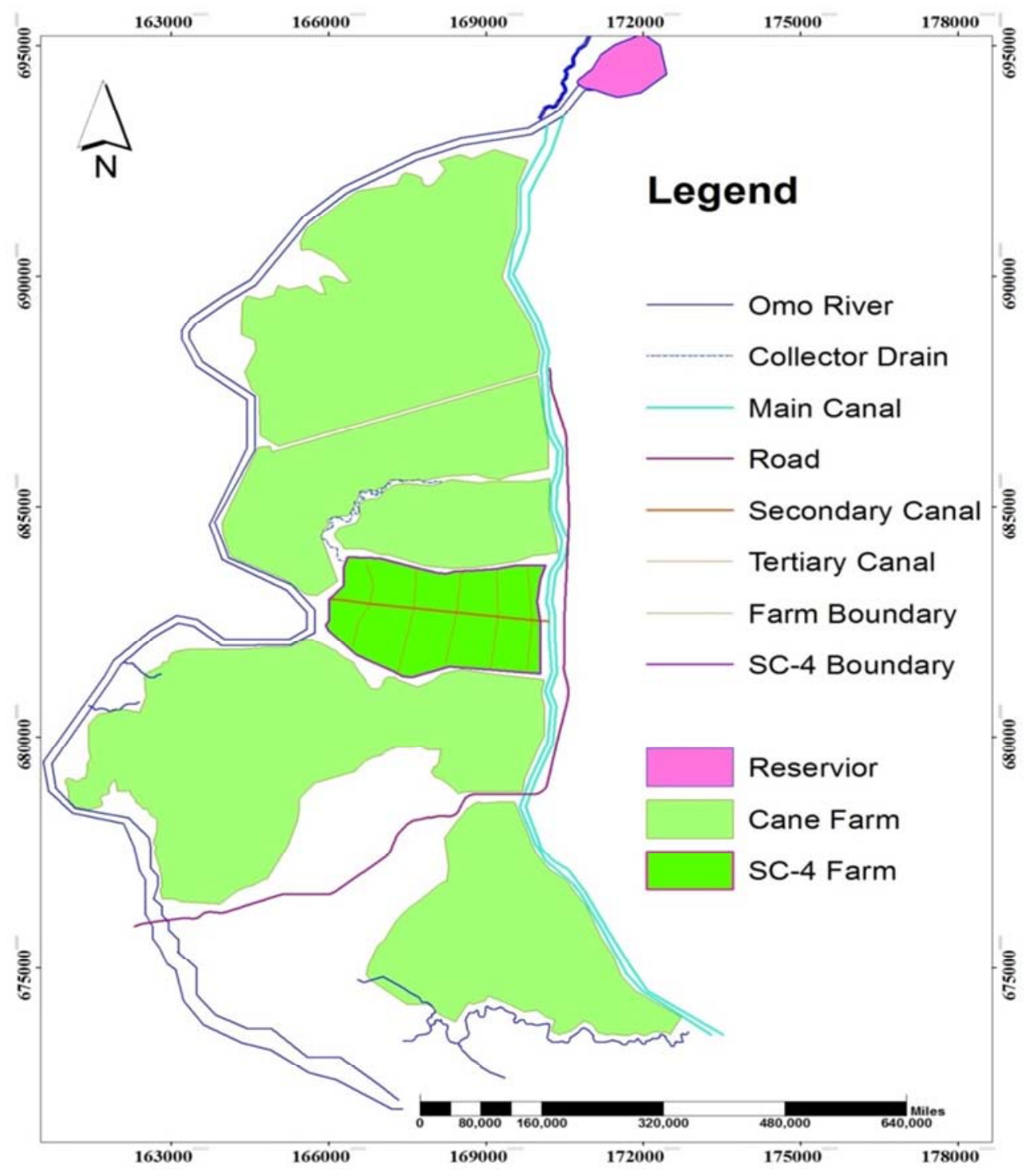

Figure 1. The irrigation Scheme layout. 


\section{Materials and Methods}

\subsection{Description of the Study Area}

This study was conducted at Omo Kuraz Sugar project, it is found in South Omo Zone in the plain areas of the lower Omo basin of the Southern Nations Nationalities and Peoples Region, which is between $5^{\circ} 56^{\prime} 00^{\prime \prime}-6^{\circ} 20^{\prime} 00^{\prime \prime}$ latitude and $35^{\circ} 44^{\prime}$ $00 "$ " $36^{\circ} 16^{\prime} 00^{\prime \prime}$ longitude and its elevation ranges from $370-500$ m.a.s.

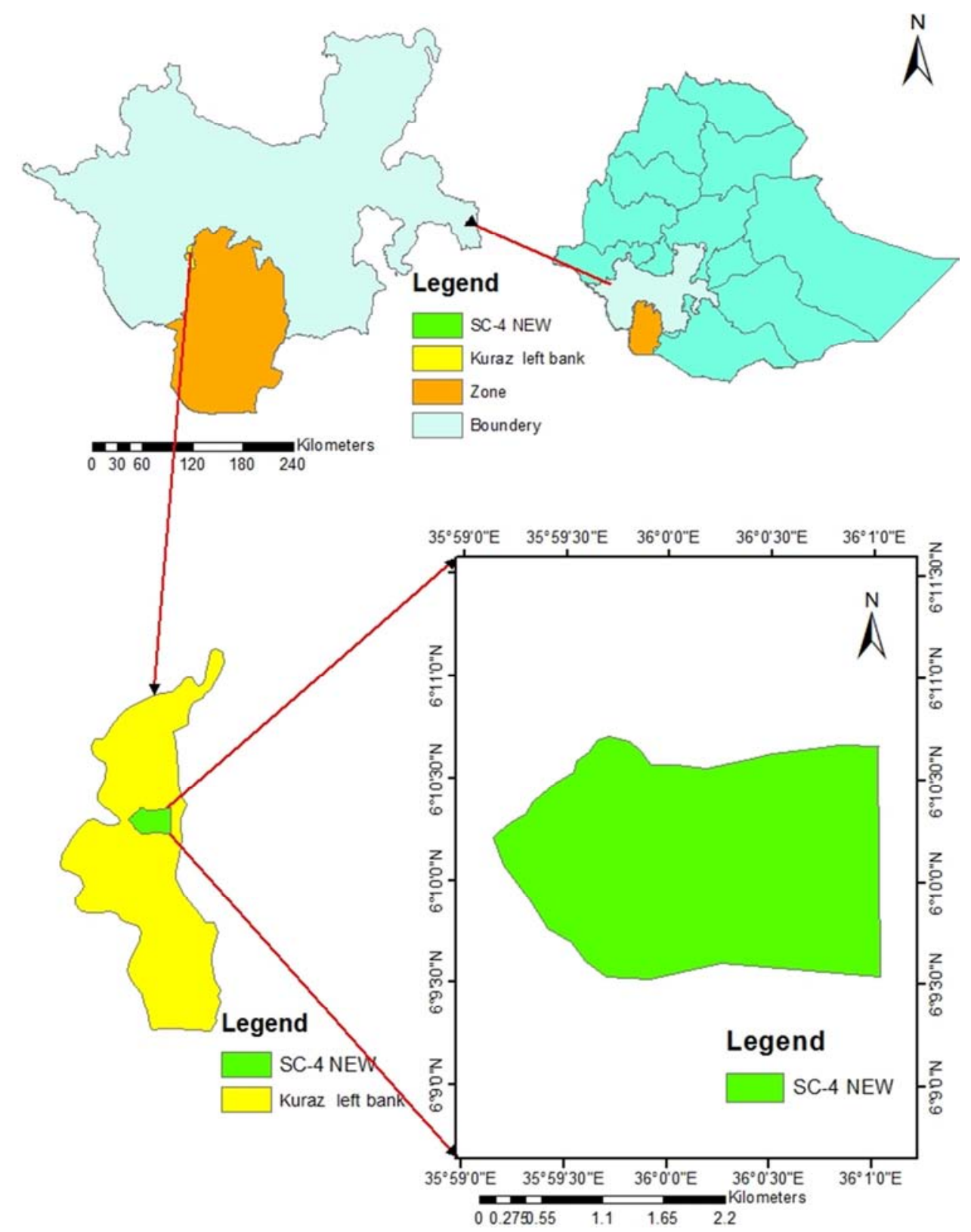

Figure 2. Location map of the study area.

\subsection{Methods}

\subsubsection{Methods of Data Collection}

Data were collected from the two sources, which are primary and secondary sources. The primary data were collected in direct measurement of discharge, water surface elevation at the head, middle and tail reach of secondary and tertiary canal and field observation of functionality and nonfunctionality of structures of the irrigation system. The secondary data were collected was design documents filed from the office of sugar project, Climate data, actual command areas, standard values of performance indicators and designed features of the scheme in the design document are major data which were utilized in the study.

\subsubsection{Discharge Measurements}

In this study, two methods were used for measuring canal irrigation water supply. These are: - $90^{\circ} \mathrm{V}$-notch weir and current meter (SEBA Universal current meter F1). By using 
current meter, velocity measured with current meter and flow area was computed from the flow geometry. The cross section of a canal was divided into a number of verticals, at which water depths and depth-averaged velocities are measured. The flow between any two adjacent verticals is a product of the width between verticals, the mean of water depths of two adjacent verticals and the mean of the average velocities over those two verticals. The total discharge at the section was determined as a sum of the discharges in each sub section. A $90^{\circ} \mathrm{V}$-Notch was used to measure flow the discharge through each off-take along the tertiary canals. According to the established water delivery plan, this flow depth is measured three times per month with the interval of ten days.

\subsubsection{Water Surface Elevation Measurements (WSE)}

During irrigation, water surface elevation of the secondary canal was measured in the reaches at head, middle and tail. Actual WSE data were taken from selected reaches in a given interval. The actual WSE data were taken from 8 measuring stations sub divided into 3 segments with $1.11 \mathrm{k} . \mathrm{m}$ interval length of the canal. From each reach, the data were taken from 8 monitoring stations at the interval $150 \mathrm{~m}$. The first measurement was taken 25 meter far from the secondary head regulator (HR). Generally, actual WSE data were taken on 24 inspection stations along the secondary canal in head, middle and tail reaches.

\subsubsection{Field Observation}

The conditions of existing irrigation scheme structures were inspected during irrigation water application time. Overall operational activities were identified and a number of functional and non-functional structures in the scheme were documented and recorded.

\subsection{Data Analysis and Interpretation}

For evaluating the hydraulic performance of the irrigation system, several performance indicators are evaluated according to the following three groups [8-10]: (I) Utility of water supply (i.e. Adequacy, Dependability, Equity, Equity ratio at head and tail, efficiency and deficiency), (II) Conveyance of water supply (i.e., conveyance efficiency and conveyance loss) and (III) maintenance performance indicator of the system (i.e. Water surface elevation ratio, Efficiency of infrastructure, Sustainability of irrigable area, Delivery Duration ratio and Overall reliability).

\subsubsection{Utility of Water Supply}

\section{1) Adequacy (PA)}

Adequacy is an indicator for a utility of water supply system whether it achieved a target or required water delivery over a certain period of time. In this study the time frame to be considered with in a period of three months. It relates to the actual to delivery desired amounts of water needed for crop irrigation to delivery points in the system [11]

$$
P A=\frac{1}{T} \sum_{T}\left(\frac{1}{R} \sum_{R}\left(\frac{Q D}{Q R}\right)\right)
$$

Where, If $\mathrm{QD} \leq \mathrm{QR}$, otherwise $\mathrm{PA}=1, \mathrm{PA}$ is the adequacy performance indicators, $\mathrm{T}$ is time and $\mathrm{R}$ is site where canals are located. QD is actual amount of water delivered by the system and $\mathrm{QR}$ is the amount of water required for crop

2) Dependability (PD)

It is defined as the temporal uniformity of the ratio of the delivered amount of water to the required amount [12]. This performance measurement indicates the uniformity of $\mathrm{QD} / \mathrm{QR}$ over time. The dependability parameter is defined:

$$
P D=\frac{1}{R} \sum_{i=R} C v T \frac{Q D}{Q R}
$$

Where, QD is actual amount of water delivered by the system and QR is the amount of water required for crop consumptive use, $C v T$ is temporal coefficient of variation (ratio of standard deviation to mean) of the ratio $\mathrm{QD} / \mathrm{QR}$ over discrete location in a region $\mathrm{R}$ and a time span $\mathrm{T}$.

3) Equity (PE)

Equity describes the degree of variability in relative water delivery from point to point over the region. The coefficient of variation $(\mathrm{CV})$ of the ratio of delivered (QD) to required $(\mathrm{QR})$ over an area $\mathrm{R}$ and time $\mathrm{T}$. The value of PE is close to zero, the greater the degree of equity (special uniformity) of water delivery. The measure is given by:

$$
P E=\frac{1}{T} \sum_{T} C v R\left(\frac{Q D}{Q R}\right)
$$

Where $\mathrm{CVR}=$ special coefficient of variation of the ratio of delivered water to required water $(\mathrm{QD} / \mathrm{QR})$ over the region R.

4) Equity Ratio for Head to Tail (ERHT)

It focused on the equity of water distribution for head and tail at different levels of a system. An equity ratio for head to tail (ERHT) components of a distribution sub-system is given as:

$$
\operatorname{ERHT}(M D R)=\frac{\frac{1}{n} \sum_{t=1}^{t=n} \operatorname{MDR}(\text { head })}{\frac{1}{n} \sum_{t=1}^{t=n} \operatorname{MDR}(\text { tail })}
$$

Where $\mathrm{t}$ is the time period, $\mathrm{n}$ is the number of periods monitored while, MDR is discussed as: Management Delivery Ratio (MDR): Conveys similar information to Delivery Performance Ratio, according to $[13,14]$, the ratio is described as:

$$
M D R=\frac{Q D}{Q R}
$$

Where, QD is the actual volume of water delivered and $\mathrm{QR}$ is the required volume of water to be delivered.

5) Deficiency

It is given as the ratio of water deficiency to the required amount. A measure of deficiency is considered as the temporal and spatial average of the ratio of (QR-QD) and QR [15]. 


$$
P D F=\frac{1}{T} \sum_{T}\left(\frac{1}{R} \sum_{R} \frac{Q R-Q D}{Q R}\right)
$$

If $\mathrm{QR}>\mathrm{QD}$, Otherwise $=0$

The expression gives water deficiency over the system in each period and overall deficiency over the period.

6) Efficiency

It is commonly interpreted as the volume of water stored in the soil for evapotranspiration compared to the volume of water delivered to this purpose [15-17]. The ratio is given as:

$$
P F=\frac{1}{T} \sum_{T=0}^{T}\left(\frac{1}{R} \sum_{R=1}^{R} \frac{Q R}{Q D}\right)
$$

If $\mathrm{QR}<\mathrm{QD}$, Otherwise, $\mathrm{PF}=1$

Where, $\mathrm{PF}$ is the spatial and temporal average of the ratio $\mathrm{QR} / \mathrm{QD}$. The more the value of PF closer to unit, the more the system becomes efficient. A delivery system for which $\mathrm{PF}$ values ranges between 0.7 and 0.84 is measured as fairly efficient [11].

\subsubsection{Conveyance Indicators}

\section{1) Conveyance Efficiency}

Conveyance efficiency is the total amount of water flowing in to a canal system at a given point divided by the amount of water reaching a certain distance downstream of a previous point. As a performance indicator, Ec is assessed by measuring inflow and outflow of selected canal reaches and calculated using Equation 8 developed by [10].

$$
E c=\frac{\text { Qout }}{\text { Qin }} * 100
$$

Where; Ec is the conveyance efficiency expressed as a percentage [\%], Qin is the total water flowing into a specific section of the canal $\left(\mathrm{m}^{3} \cdot \mathrm{s}^{-1}\right)$, and $\mathrm{Q}_{\text {out }}$ is the total water flowing out of a specific section of the canal $\left(\mathrm{m}^{3} \mathrm{~s}^{-1}\right)$.

2) Conveyance loss

It measures the efficiency of the canal system to convey water and shows the of water loss over a given travel distance. A water conveyance loss ratio can be calculated for each section of the secondary canal using Equation 9 [18].

$$
W L c=\frac{\text { Qin }- \text { Qout }}{\text { Qin }} * 100
$$

Where WLc is the water conveyance loss ratio expressed as a percentage [\%], and Qin and Qout are as previously defined in equation 8 .

\subsubsection{Maintenance Indicators}

Proper maintenance enables the keeping of water control and distribution infrastructure in good working condition so that the design water level is maintained. The hydraulic performance of the scheme could also be evaluated through maintenance performance indicators; the performance was estimated through the indicators recommended [8-10].

1) Effectiveness of Infrastructure

It measures the ratio of the number of functioning structures to the total number of structures initially installed. The efficiency of infrastructure was calculated as:

$$
\mathrm{EI}=\frac{\text { Number of Function Structures }}{\text { Total } \text { Number of Structures }}
$$

2) Water Surface Elevation Ratio (WSER)

The parameter is defined by measuring the actual water surface elevation at intended water level recorded below the FSL [20]. If WSER $>1$, indicate an erosion problem. and if WSER $<1$, then there is a probability of rising canal bed level due to siltation and weed incidence in a canal. WSER can be calculated as:

$$
\mathrm{WSER}=\frac{\text { Actual } \text { Water Surface Elevation at } F S L}{\text { Target } \text { Water Surface Elevation at } F S L}
$$

3) Delivery Duration Ratio or Dependability Duration (DDR)

This parameter is estimated as the ratio of the duration of actual irrigation water delivered to the intended duration of water delivery.

$$
D D R=\frac{D a c}{\operatorname{Din}}
$$

Where, Dac is actual duration of water delivered (day) and Din is intended duration of supply (day)

4) Sustainability of Irrigated Area (SIA)

It is the ratio of currently irrigated area to initially irrigated area when designed [10].

$$
\mathrm{SI}=\frac{\text { Actual.Irrigated } \cdot \text { Area }}{\text { Designed.Irrigated.Area }}
$$

Table 1. Range of Performance Indicators.

\begin{tabular}{lllll}
\hline \multirow{2}{*}{ Indicators } & Ranges & Fair & Good & Excellent \\
\cline { 2 - 5 } & Poor & $0.11-0.20$ & $0.00-0.10$ & $0.90-1.00$ \\
PD & $>0.20$ & $0.80-0.89$ & $0.00-0.10$ & \\
PA & $<0.80$ & $0.11-0.25$ & $0.85-1.00$ & $0.8-0.9 \& 1.1-1.2$ \\
PE & $>0.25$ & $0.70-84$ & & $0.9-1.10$ \\
PF & $<0.70$ & $0.7-0.79 \& 1.21-1.3$ & \\
ERHT (MDR) & $<0.7$ or $>1.3$ & 1 & & \\
DDR & 0 or $>1.0$ &
\end{tabular}

Source: Mohsen et al. (2012) and Molden and Gates (1990) 


\subsection{Estimation of Irrigation Water Requirement}

The crop water requirement was computed from secondary data using CROPWAT 8.0. The reference evapotranspiration (ETo) for the succeeding months was estimated using the FAO Penman-Monteith method [21]. The crop water requirement (ETc) was computed by using (in equation 14) from the ETo and the crop factor $(\mathrm{Kc})$ values for each growing stages of sugarcane crop during irrigation season.

$$
E T C=E T O^{*} K c
$$

Where, ETc is crop water requirement, ETo is evapotranspiration and $\mathrm{Kc}$ is crop coefficient

According to equation 15, the irrigation requirement (IR) indicates the difference between the Evapotranspiration of the crop under ideal conditions (ETc) and the effective rainfall ( $\left(\mathrm{Ef}_{\mathrm{eff}}\right)$ contributions during the same time period [22] and it is expressed in $\mathrm{mm}$ or $\mathrm{m}^{3}$.

$$
\begin{gathered}
I R=E T C-R f_{e f f} \\
G I R=\frac{I R}{E i}
\end{gathered}
$$

Where, GIR is gross irrigation requirement and Ei efficiency of irrigation (0.8)

Then, irrigation requirement $(1 / \mathrm{s} / \mathrm{h})$ to feed each tertiary outlet was converted into flow rate by multiplying the area which was fed the tertiary off takes. The flow was the product of GIR in 1/s/ha per month and the command area (ha) served for irrigation (in equation 17). As a final point, to evaluate water delivery performance indicator, the flow rate was converted in to volume $\left(\mathrm{QR}\right.$, in $\left.\mathrm{m}^{3}\right)$.

$$
Q R=G I R^{*} A
$$

Where, QR is the required discharge, IR is irrigation water requirement and $\mathrm{A}$ is areas covered by crop (sugarcane)

\section{Result and Discussion}

\subsection{Evaluation of Irrigation Scheme Performance}

The results of this study was based on the delivered discharge, required discharge of the secondary canal and tertiary canals, the irrigated area and total command area, duration of water supply; and functional and total structures of the irrigation system. The required amount of water $(\mathrm{QR})$ for the growing season was calculated using CROPWAT 8 program (Clarke, 1998). Crop water requirement was computed for sugarcane plant with different growing stages in the command areas and then total sum of irrigation water requirements of each off take of tertiary canal was calculated. The volume of water required $(\mathrm{QR})$ by the tertiary canals at each measuring points was the product of IR and the command area served for irrigation. Secondary canal system performance was estimated based on the monthly required discharge. These outcomes are the averages of three consecutive months i.e., June, July and August 2019. Then, the performance indicators under conveyance, utility and maintenance category could be discussed in the following section using a statically approach.

\subsection{Rainfall Data Analysis}

In Kuraz scheme the mean minimum and maximum rainfall amount occurred in months of January $(9.6 \mathrm{~mm})$ and April (229.07 mm), respectively. Kuraz irrigation scheme has an average total annual rainfall of $974.13 \mathrm{~mm}$. The mean total annual effective rainfall amount of the study area was $788.2 \mathrm{~mm}$. Hence this effective rainfall contributed to support the crop water demand in the irrigation seasons.

\begin{tabular}{|c|c|c|c|c|c|c|c|c|c|c|c|c|c|c|c|c|c|c|c|c|}
\hline \multirow{3}{*}{ Month } & \multicolumn{8}{|l|}{ Head } & \multicolumn{4}{|c|}{ Middle } & \multicolumn{8}{|l|}{ Tail } \\
\hline & TC1 & & TC2 & & TC3 & & TC4 & & TC5 & & TC6 & & TC7 & & TC8 & & TC9 & & TC10 & \\
\hline & $\mathbf{Q}_{\mathrm{D}}$ & $\mathbf{Q}_{\mathrm{R}}$ & $\mathbf{Q}_{\mathrm{D}}$ & $\mathbf{Q}_{\mathrm{R}}$ & $\mathbf{Q}_{\mathrm{D}}$ & $\mathbf{Q}_{\mathrm{R}}$ & $\mathbf{Q}_{\mathrm{D}}$ & $\mathbf{Q}_{\mathrm{R}}$ & $\mathbf{Q}_{\mathrm{D}}$ & $\mathbf{Q}_{\mathrm{R}}$ & $\mathbf{Q}_{\mathrm{D}}$ & $\mathbf{Q}_{\mathrm{R}}$ & $\mathbf{Q}_{\mathrm{D}}$ & $\mathbf{Q}_{\mathrm{R}}$ & $\mathbf{Q}_{\mathbf{D}}$ & $\mathbf{Q}_{\mathrm{R}}$ & $\mathbf{Q}_{\mathrm{D}}$ & $\mathbf{Q}_{\mathrm{R}}$ & $\mathbf{Q}_{\mathrm{D}}$ & $\mathbf{Q}_{\mathrm{R}}$ \\
\hline June & 0.04 & 0.027 & 0.028 & 0.032 & 0.039 & 0.026 & 0.041 & 0.023 & 0.045 & 0.03 & 0.035 & 0.023 & 0.025 & 0.029 & 0.04 & 0.027 & 0.026 & 0.017 & 0.016 & 0.019 \\
\hline July & 0.046 & 0.025 & 0.046 & 0.03 & 0.021 & 0.024 & 0.034 & 0.021 & 0.048 & 0.028 & 0.042 & 0.022 & 0.036 & 0.027 & 0.049 & 0.025 & 0.041 & 0.016 & 0.038 & 0.017 \\
\hline August & 0.054 & 0.03 & 0.058 & 0.037 & 0.049 & 0.029 & 0.053 & 0.026 & 0.043 & 0.034 & 0.046 & 0.026 & 0.042 & 0.033 & 0.041 & 0.03 & 0.043 & 0.019 & 0.042 & 0.021 \\
\hline
\end{tabular}

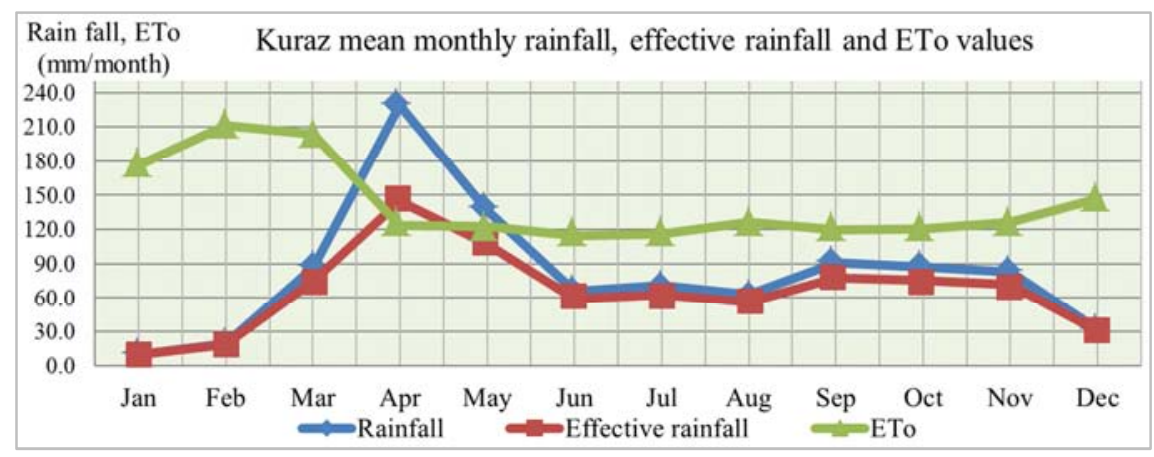

Figure 3. Kuraz scheme mean monthly rainfall, effective rainfall and ETo values.

Table 2. Average delivered and required discharge in each tertiary canal off-take $\left(\mathrm{m}^{3} / \mathrm{s}\right)$.

Where, $\mathrm{Q}_{\mathrm{D}}$ and $\mathrm{Q}_{\mathrm{R}}$ is the delivered and required discharge from the off taking point of tertiary canal $\mathrm{TC}_{\mathrm{i}}$ is tertiary canal and $\mathrm{i}$ is $1,2,3 \ldots 10$ 


\subsubsection{Utility of Water Supply Indicators}

1) Adequacy (PA)

According to Molden and Gates (1990), adequacy value was calculated using equation (1); the spatial and temporal mean values of PA in each tertiary canal off take and head, middle and tail reach of the system are given in Table 2 below.

Table 3. Average adequacy of water distribution in the system.

\begin{tabular}{|c|c|c|c|c|c|c|c|c|c|c|c|}
\hline \multirow{2}{*}{ Month } & \multicolumn{4}{|l|}{ Head } & \multicolumn{2}{|c|}{ Middle } & \multicolumn{4}{|l|}{ Tail } & \multirow{2}{*}{$\begin{array}{l}\text { Spatial } \\
\text { Ave }\left(P_{A}\right)\end{array}$} \\
\hline & TC1 & TC2 & TC3 & TC4 & TC5 & TC6 & TC7 & TC8 & TC9 & TC10 & \\
\hline Jun & 1.00 & 0.86 & 1.00 & 1.00 & 1.00 & 1.00 & 0.8 & 1.00 & 1.00 & 0.86 & 0.95 \\
\hline Jul & 1.00 & 1.00 & 0.88 & 1.00 & 1.00 & 1.00 & 1.00 & 1.00 & 1.00 & 1.00 & 0.99 \\
\hline Aug & 1.00 & 1.00 & 1.00 & 1.00 & 1.00 & 1.00 & 1.00 & 1.00 & 1.00 & 1.00 & 1.00 \\
\hline Temporal Average & 1.00 & 0.95 & 0.96 & 1.00 & 1.00 & 1.00 & 0.9 & 1.00 & 1.00 & 0.95 & \\
\hline Average (PA) & 0.98 & & & & 1.00 & & 0.97 & & & & 0.98 \\
\hline
\end{tabular}

The average values of spatial adequacy were $0.95,0.99$ and 1.00 in June, July and August and temporal adequacy values are $0.98,1.00$ and 0.97 at head, middle and tail reach of the system respectively. The overall adequacy value of the system was 0.98 . According to the performance evaluation standards set by Molden and Gates (1990), overall average of PA (0.98) mentioned in Table 1, is at a good range which indicates the amount of water delivered during the study period at adequate amount throughout the system.
2) Dependability (PD)

Values of dependability for the three sections under the study were $0.041,0.00$ and 0.05 respectively (Table 4). According to equation 2, the average dependability for tertiary canals except TC2, TC3, and TC7 \& TC10 is zero. The maximum average dependability of tertiary canal off take was found to be 0.12 and overall average dependability of the system was 0.03 .

Table 4. Average dependability of water distribution in the system

\begin{tabular}{|c|c|c|c|c|c|c|c|c|c|c|c|c|c|}
\hline \multirow{2}{*}{ Month } & \multicolumn{4}{|l|}{ Head } & \multicolumn{2}{|c|}{ Middle } & \multicolumn{4}{|l|}{ Tail } & \multirow{2}{*}{ Ave } & \multirow{2}{*}{ SD } & \multirow{2}{*}{$\begin{array}{l}\text { CV } \\
\text { (PE) }\end{array}$} \\
\hline & TC1 & TC2 & TC3 & TC4 & TC5 & TC6 & TC7 & TC8 & TC9 & TC10 & & & \\
\hline Jun & 1.0 & 0.86 & 1.0 & 1.0 & 1.0 & 1.0 & 0.8 & 1.0 & 1.0 & 0.86 & 0.95 & 0.1 & 0.08 \\
\hline Jul & 1.0 & 1.0 & 0.88 & 1.0 & 1.0 & 1.0 & 1.0 & 1.0 & 1.0 & 1.0 & 0.99 & 0.0 & 0.04 \\
\hline Aug & 1.0 & 1.0 & 1.0 & 1.0 & 1.0 & 1.0 & 1.0 & 1.0 & 1.0 & 1.0 & 1.0 & 0.0 & 0.00 \\
\hline Ave. & 1.0 & 0.95 & 0.96 & 1.0 & 1.0 & 1.0 & 0.93 & 1.0 & 1.0 & 0.95 & & & 0.04 \\
\hline SD & 0.0 & 0.08 & 0.07 & 0.0 & 0.0 & 0.0 & 0.12 & 0.0 & 0.0 & 0.08 & & & \\
\hline CV (PD) & 0.0 & 0.09 & 0.07 & 0.0 & 0.0 & 0.0 & 0.12 & 0.0 & 0.0 & 0.08 & & & \\
\hline
\end{tabular}

According to water delivery performance standards given by Molden \& Gats (1990), the dependability of flow was fair at TC7 which indicates that low level of dependability may have been caused by improper timeliness in water allocation by the water allocation and distribution. Whereas, the values of temporal coefficient of variation of water delivered all tertiary canals offtakes' were in the ranges between $0.00-0.10$ and whose dependability were good. Over all dependability of the system was found to be good.

3) Equity (PE)

Equitable water distribution is reached when the ratio of water delivery to water required in the outlets equal to one over the system [11]. The equity indicator for three successive months (June, July and August) and also overall equity were evaluated. Using the equation 3 , the coefficient of spatial water distribution for cane farms the values PE ranged in between 0 and 0.08 (Table 4). According to Molden and Gates (1990) performance range classification in Table 1., equity of water distribution in June, July and August are $0.08,0.04 \& 0.00$ respectively which lay under the range of 0.00 to 0.10 ; which goes under the category of a good performance. The overall coefficient of variation (CV) based on the delivered amount was still 'good'.

4) Equity Ratio for Head to Tail (ERHT)

This indicator provides equity in irrigation water among the tertiary canals with special focus on Head and Tail reaches of the system. It is important parameter to estimate how water was managed and delivered fairly in head and tail reach of the secondary canal. Table 5 displayed the equity ratio for head and tail and the value of MDR.

Table 5. Equity Ratio for Head to Tail reach (ERHT) of system.

\begin{tabular}{lllllllll}
\hline \multirow{2}{*}{ Month } & Head & & & & Tail & & \\
& TC1 & TC2 & TC3 & TC4 & TC7 & TC8 & TC9 & TC10 \\
\hline Jun & 1.5 & 0.86 & 0.66 & 0.6 & 1.19 & 0.7 & 0.66 & 1.2 \\
Jul & 1.87 & 1.55 & 0.88 & 1.6 & 1.32 & 2.0 & 2.56 & 2.2 \\
Aug & 1.8 & 1.58 & 1.66 & 2.0 & 1.27 & 1.3 & 2.21 & 2.0 \\
Ave. & & & & & & & & \\
\hline
\end{tabular}


From Table 5 the estimated value of ERHT for June, July and August are 0.97, 0.73 and 1.03 respectively. The average value of ERHT is 0.91. The overall average value is 0.91 which lies in between $0.8-0.9 \& 1.1-1.2$, so the system has a good performance. However, during July month result of ERHT obtained in Table 5 is 0.73 which is satisfactory.

5) Deficiency
The parameter helps the system managers and users to take corrective measurements for improving the system in the deficit area. As the value of PDF equal to or close to 0.00 , supply is uniform at each off-take. However, PDF value is greater than zero (PDF $>0$ ) a deficiency in supply was happened. In this case, crops may suffer from water stress [15].

Table 6. Average spatial and temporal Deficiency (PDF) of system.

\begin{tabular}{|c|c|c|c|c|c|c|c|c|c|c|c|}
\hline \multirow{2}{*}{ Month } & \multicolumn{4}{|l|}{ Head } & \multicolumn{2}{|c|}{ Middle } & \multicolumn{4}{|l|}{ Tail } & \multirow{2}{*}{ Spatial Ave } \\
\hline & TC1 & TC2 & TC3 & TC4 & TC5 & TC6 & TC7 & TC8 & TC9 & TC10 & \\
\hline Jun & 0.00 & 0.14 & 0.00 & 0.00 & 0.00 & 0.00 & 0.16 & 0.00 & 0.00 & 0.14 & 0.04 \\
\hline Jul & 0.00 & 0.00 & 0.12 & 0.00 & 0.12 & 0.00 & 0.00 & 0.00 & 0.00 & 0.00 & 0.02 \\
\hline Aug & 0.00 & 0.00 & 0.00 & 0.00 & 0.00 & 0.00 & 0.00 & 0.00 & 0.00 & 0.00 & 0.00 \\
\hline Temporal Ave. at TC & 0.00 & 0.05 & 0.04 & 0.00 & 0.04 & 0.00 & 0.05 & 0.00 & 0.00 & 0.05 & 0.02 \\
\hline At reaches & 0.02 & & & & 0.02 & & 0.02 & & & & \\
\hline
\end{tabular}

As per Table 6, the temporal averaged values of deficiency at the tertiary outlet points were ranges from $0.00(0 \%)$ to $0.05(5 \%)$. The higher deficit was observed at tertiary outlet points TC2, TC3, TC5, TC7 and TC10 and all the remaining outlet points had the lowest values $(0 \%)$.

In general average overall deficiency of the delivery system was found to be 0.02 . During the three successive months the system has been supplied ninety eight percent $(98 \%)$ of the total required amount of irrigation water. Only two percent $(2 \%)$ of the irrigated commands has not been satisfied by the system. Therefore, system has negligible amount of deficiency and performance of the system is satisfactory.

6) Efficiency

The parameter shows how the water resource would be conserved [14] and knowing how the system was conveyed a required amount.

Table 7. Average spatial and temporal efficiency of the system.

\begin{tabular}{|c|c|c|c|c|c|c|c|c|c|c|c|}
\hline \multirow{2}{*}{ Month } & \multicolumn{4}{|l|}{ Head } & \multicolumn{2}{|c|}{ Middle } & \multicolumn{4}{|l|}{ Tail } & \multirow{2}{*}{$\begin{array}{l}\text { Spatial } \\
\text { Ave (PF) }\end{array}$} \\
\hline & TC1 & TC2 & TC3 & TC4 & TC5 & TC6 & TC7 & TC8 & TC9 & TC10 & \\
\hline Jun & 0.67 & 1.00 & 1.00 & 1.00 & 0.66 & 1.00 & 0.57 & 1.00 & 0.67 & 1.00 & 0.86 \\
\hline Jul & 0.53 & 1.00 & 0.65 & 0.71 & 1.00 & 1.00 & 0.63 & 1.00 & 0.58 & 1.00 & 0.81 \\
\hline Aug & 0.56 & 0.63 & 0.63 & 1.00 & 0.60 & 1.00 & 0.50 & 1.00 & 0.79 & 1.00 & 0.77 \\
\hline Temporal Average & 0.59 & 0.88 & 0.76 & 0.90 & 0.75 & 1.00 & 0.56 & 1.00 & 0.68 & 1.00 & \\
\hline Average (PF) & 0.78 & & & & 0.88 & & 0.81 & & & & 0.81 \\
\hline
\end{tabular}

The monthly spatial average efficiency values were gradually declined from June to August. The values show that the efficiency spatially perceived in June was rated as 'good' (higher than 0.84). The efficiency of water supplied in the head and tail reaches were rated as fair. This problem was leakage due to uncontrolled delivery of water in the tertiary canal outlet of TC1, TC3, TC7 and TC9 (Table 7). The overall efficiency (PF) of a system was estimated to be 81 percent. Based on Molden and Gates (1990) suggested the range of performance evaluation criteria, the efficiency performance value found was considered as fair.

\subsubsection{Conveyance Indicators}

The main purpose of the conveyance system is to transport the delivered amount of the location of crop field. In unlined earthen canal, part of water conveyed is lost and reduced amount of water reaches to the field.

Conveyance efficiency and conveyance losses were calculated as shown in (8) and (9) respectively. The estimated average values of inflow, outflow, water conveyance efficiency and water conveyance losses for different section of the secondary canal are presented in Table 8. In Left bank of Omo Kuraz irrigation scheme, the conveyance efficiency of the secondary canal four (SC-4) was decreased as far from head to tail reaches of the canal. The mean observed conveyance efficiency ranges from $75-85.31 \%$, the minimum value occurred during June month at the tail reach (From $2+350$ to $3+33 \mathrm{~m}$ ) of secondary canal. This is because of the reach of the canal was cracked which resulted seepage and leakage losses. The overall average value of conveyance efficiency of the $3.33 \mathrm{~km}$ Secondary canal was $81.20 \%$. The canal losses were $18.80 \%$ of the water through seepage due to the fact that it is an earthen canal. Siltation and vegetation growth within the canal interferes with water flow reducing the conveyance efficiency. According to the FAO guidelines, the indicator parameter values of the conveyance efficiency for adequately maintained earthen canals having more than $2000 \mathrm{~m}$ canal length with clay soils should be $80 \%$. This indicates that the maintenance at secondary canal was adequate and therefore there was no need of routine maintenance. 
Table 8. Conveyance Efficiency of Secondary canal.

\begin{tabular}{|c|c|c|c|c|c|c|}
\hline Month & Chain- age (m) & Location & Inflow $\left(\mathrm{m}^{3} / \mathrm{s}\right)$ & Outflow $\left(\mathrm{m}^{3} / \mathrm{s}\right)$ & Ec (\%) & Lc (\%) \\
\hline \multirow{6}{*}{ June } & From $0+20$ to $0+150$ & Between HR and BD-1 & 0.46 & 0.385 & 83.7 & 16.3 \\
\hline & From $0+150$ to $0+850$ & Between BD-1 and BD-2 & 0.34 & 0.28 & 82.35 & 17.65 \\
\hline & From $0+850$ to $1+650$ & Between DB-2 and BD-3 & 0.22 & 0.177 & 80.45 & 19.55 \\
\hline & From $1+650$ to $2+350$ & Between DB-3 and BD-4 & 0.11 & 0.087 & 79.09 & 20.91 \\
\hline & From $2+350$ to $3+330$ & BetweenDB-4 and BD-5 & 0.06 & 0.045 & 75 & 25 \\
\hline & & & & & 80.1 & 19.9 \\
\hline \multirow{6}{*}{ July } & From $0+20$ to $0+150$ & Between HR and BD-1 & 0.51 & 0.43 & 84.31 & 15.69 \\
\hline & From $0+150$ to $0+850$ & Between BD-1 and BD-2 & 0.37 & 0.31 & 82.43 & 17.57 \\
\hline & From $0+850$ to $1+650$ & Between DB-2 and BD-3 & 0.26 & 0.21 & 79.83 & 20.17 \\
\hline & From $1+650$ to $2+350$ & Between DB-3 and BD-4 & 0.09 & 0.07 & 81.11 & 18.89 \\
\hline & From $2+350$ to $3+330$ & BetweenDB-4 and BD-5 & 0.07 & 0.06 & 81.43 & 18.57 \\
\hline & & & & & 81.8 & 18.2 \\
\hline \multirow{5}{*}{ August } & From $0+20$ to $0+150$ & Between HR and BD-1 & 0.57 & 0.48 & 84.21 & 15.79 \\
\hline & From $0+150$ to $0+850$ & Between BD-1 and BD-2 & 0.41 & 0.34 & 82.93 & 17.07 \\
\hline & From $0+850$ to $1+650$ & Between DB-2 and BD-3 & 0.32 & 0.26 & 81.14 & 18.86 \\
\hline & From $1+650$ to $2+350$ & Between DB-3 and BD-4 & 0.18 & 0.14 & 81.37 & 18.63 \\
\hline & From $2+350$ to $3+330$ & BetweenDB-4 and BD-5 & 0.07 & 0.06 & 78.57 & 21.43 \\
\hline \multirow{2}{*}{\multicolumn{2}{|c|}{ Overall average }} & & & & & 18.4 \\
\hline & & & & & 81.2 & 18.8 \\
\hline
\end{tabular}

\subsubsection{Maintenance Indicators}

Maintenance performance inspection of irrigation scheme is important to insight the feature of maintenance situations. Inspection of the maintenance statuses of the system was required to identify the problems. The maintenance innovation of a system have a duty undertaking for the purposes of safety improvement, keeping water control, distribution and other infrastructures in good working condition designed in sustainable base [19]. In order to improvement system performance in this study, maintenance requirement was observed according to the maintenance indicators of effectiveness of infrastructure, water surface elevation ratio, delivery duration ratio and sustainability of irrigated area.

1) Effectiveness of Infrastructure

Effectiveness of infrastructure is measured by the ratio of the number of functioning structures to the total number of structures initially constructed. The total number of structures that were initially constructed on Irrigation scheme was 142 . Out of 142, only 118 structures are functional (shown in Table 9). The average values of effectiveness of infrastructures estimated to be $89.68 \%$ which indicates that the maintenance activity of the system was fair.

Table 9. Functional and mal-functional irrigation infra structures.

\begin{tabular}{llllll}
\hline SN & Infra structures & Total number of installed structures & Functional & Mal-functional & effectiveness of infra structures \\
\hline 1 & Secondary head regulator & 1 & 1 & 0 & 100 \\
2 & Secondary cross regulator & 5 & 4 & 1 & 80 \\
3 & Division box & 5 & 5 & 0 & 100 \\
4 & Tertiary head regulator & 10 & 9 & 1 & 90 \\
5 & Quaternary regulator & 35 & 26 & 9 & 74.3 \\
6 & Tertiary cross regulator & 35 & 26 & 9 & 74.3 \\
7 & Drop structures & 6 & 6 & 0 & 100 \\
8 & Tertiary off takes & 10 & 10 & 0 & 100 \\
9 & Quaternary off takes & 35 & 31 & 4 & 88.6 \\
& Total & 142 & 118 & 24 & 89.68 \\
\hline
\end{tabular}

In addition to the above calculation, the existing condition of irrigation infrastructures of the scheme was also evaluated by setting condition grade for the infrastructures. A condition assessment was conducted using a top down approach based upon staff knowledge, maintenance records, customer complaints (water users) and performance records. A physical check was conducted whenever routine maintenance was done. Information collected on the condition was recorded in the infrastructure register and updated in the strategic plans where necessary (Internet: www.treasury.gov.za). Each infrastructure was inspected on a risk based cycle, with an accurate description of condition, and identification of specific defects. These defects were due to physical deterioration in irrigation system and inefficient management of scheme. Each and every structure including secondary and tertiary canals was evaluated by using condition determination parameter according to its physical state of structures inspected according to their original design standards. According to condition determination parameter the average condition of secondary canal, tertiary canals, division boxes, drops, tertiary and quaternary off takes, head and cross regulators on secondary canal and head and cross regulators were $81,66.8,86.6,84.8,87.4,86.8$ and 52 percent respectively. 
2) Water Surface Elevation Ratio (WSER)

WSER is important parameter to predict the impact of sedimentation, canal bed scouring problem and erosion problem on the irrigation scheme. It was calculated by measuring the actual water depth from the canal bottom on different measurement points in each individual monitoring station and comparing it with the design water depth at (FSL) at the same position in the secondary canal (equation 11).

Table 10. Average Water Surface Elevation (WSE) of the secondary canal.

\begin{tabular}{|c|c|c|c|c|c|c|c|c|c|c|c|}
\hline \multirow{2}{*}{ Station } & \multicolumn{3}{|l|}{ Head } & \multicolumn{3}{|l|}{ Middle } & \multicolumn{3}{|l|}{ Tail } & \multicolumn{2}{|l|}{ Over all } \\
\hline & Chain (m) & DEV. WSEa & WSER & Chain (m) & DEV. WSEa & WSER & Chain (m) & DEV. WSEa & WSER & WSER & DEV. WSE \\
\hline H1 & 20 & 0.01 & 1.00 & 1200 & 0.03 & 0.96 & 2300 & 0.003 & 1 & & \\
\hline $\mathrm{H} 2$ & 110 & 0.02 & 0.98 & 1350 & 0.02 & 0.98 & 2450 & 0.13 & 0.76 & & \\
\hline H3 & 250 & 0.02 & 0.98 & 1500 & 0.02 & 0.98 & 2600 & 0.01 & 0.98 & & \\
\hline H4 & 400 & 0.02 & 0.98 & 1650 & 0.02 & 0.97 & 2750 & 0.03 & 0.93 & & \\
\hline H5 & 600 & 0.01 & 0.98 & 1800 & 0.04 & 0.93 & 2900 & 0.04 & 0.9 & & \\
\hline H6 & 800 & 0.01 & 0.99 & 1950 & -0.06 & 1.11 & 3050 & 0.01 & 0.98 & & \\
\hline $\mathrm{H} 7$ & 1000 & 0.04 & 0.95 & 2100 & -0.02 & 1.03 & 3200 & 0.04 & 0.9 & & \\
\hline H8 & 1110 & 0.03 & 0.96 & 2220 & -0.03 & 1.05 & 3330 & 0.02 & 0.95 & & \\
\hline Ave. & & 0.02 & 0.98 & & 0.01 & 1.00 & & 0.04 & 0.92 & 0.965 & 0.011 \\
\hline Max. & & 0.04 & 1.00 & & 0.04 & 1.11 & & 0.13 & 1.00 & & \\
\hline
\end{tabular}

Average Parameter of WSER at head and tail reaches of the secondary canal during the monitoring period was less than one, thus it shows that the secondary canal has an effect of sedimentation problem [20]. Overall average value of WSER was found to be 0.96 which means water surface elevation was 3.5 percent was reduced in the intended water depth of the secondary canal. This indicates the canal had an effect of sediment accumulation and chocked with grass did not have maintenance schedule for sediment clearing and weed removal.

3) Dependability Duration (DDR)

Dependability Duration is the ratio of actual duration of irrigation water delivery (hours) to the intended irrigation water duration (hours).

According to the design document the intended duration of water delivery was 24 hours per day. Because entry of silt, debris and foreign material to the main canal, excess flow of river water which caused unstable full supply level in canal and deterioration of side slope material due to sudden draw down condition, the average delivery duration is reduced to 21 hours. The value of delivery duration ratio (DDR) was calculated using equation (12) Thus, DDR is 0.875; according to the standard presented in Table 1 the value is ranked 'poor'.

4) Sustainability of Irrigated Area (SIA)

SIA is an indicator used to point out the command areas planned to irrigate is either fully exhausted or not. This indicator enabled to investigate the variation in the area actually irrigated against the designed area in terms of ratio and provide valid reasons for such variation [23]. On the design document of the planned irrigable area of secondary four at Left bank Omo Kuraz irrigation scheme was 777.85 ha. The actual irrigated area in the irrigation season was 743.334ha. Hence, SIA was 95.56 percent using equation (14). The command areas were reduced because of delaying of land preparation operation 34.516ha was not planted. Hence, the maintenance of irrigation system is not the limiting factors in the reduction of irrigated area.

\section{Conclusions and Recommendations}

\subsection{Conclusions}

Assessing the performance of an irrigation scheme is important management functions which indicates the state of the scheme and suggest possible remedial measures to improve the effectiveness of the scheme. This study was to assess the performance of Omo Kuraz irrigation scheme with respect to utility of water supply indicators, conveyance indicators and maintenance indicators. Overall Performance of the scheme in terms of utility of water supply indicators of the secondary canal were found to be good in terms of adequacy, dependability, equity, equity ratio for head to tail and deficiency respectively, however, overall efficiency for the system was satisfactory performance. This was due to malfunctioning of head and cross regulators, some parts of the canal observed was braced with grass, cleaning the canals without specific standards has made some of its sections to enlarge, the absence of flow measuring devices in order to deliver only required water, bed scouring and sedimentation of parts of the reaches secondary canal and improper operation of water delivery system.

The average conveyance efficiency in the secondary canal was found to be $81.2 \%$, slightly above $80 \%$ according to FAO guidelines, it was recommended for unlined earthen canals with more than $2000 \mathrm{~m}$ canal length. It was concluded that conveyance efficiency was higher at the head reach because the canal section at the head reach was intact and having stable banks with no visible seepage. However, it was lower in the tail-reaches due to Siltation and vegetation growth within the canal interferes with water flow reducing the conveyance efficiency. The secondary canal needs maintenance to minimize water losses in the tail reach of the canal.

Performance of the scheme related with maintenance has been unsatisfactory. On average, the mean level of surface water for secondary canal has been reduced by three percent from the full supply level. From gross planned command 
areas of the irrigation scheme 34.52 ha was not covered by sugar cane which means total intended area was reduced by five percent. Therefore, proper maintenance of hydraulic gates and hoists is very essential for satisfactory operation of gates to control water heads and distribute adequate and equitable amount of water throughout the system, for their long term sustainability and continuous monitoring and maintenance is required to improve the performance.

\subsection{Recommendations}

1) Flow at every delivery tertiary outlet point (at head, middle and tail reaches of the system) should be monitored for a sustainable irrigation water management. It could be important for supplying the only amount of irrigation water which crop needs, increasing efficiency the irrigation system and also important for evaluating service delivery of the irrigation system.

2) Even if the service years of the irrigation scheme are only six years, the system has been facing a number of challenges especially those related with operating gates. Most operating sluice gates are totally nonfunctional should be maintained and completely damaged parts of the gates would be replaced by the new components would result in lower future maintenance costs, less frequent breakage, easily operated.

3) Applying proper water distribution plan in the system according to the crop required amount which might be vital for improving proportional irrigation water supply and demand among tertiary outlet. The crop water requirement varies according to its growth stages; hence the rotation shall be based on crop water demands in the area.

4) In order to reduce water losses, the secondary canal at the tail reach should be regularly maintained. At high fill reaches of the canal should be lined in order to be more effective and permanently reduce water conveyance losses.

5) The physical restoration and implementation of new management technique must be included in the operational changes.

\section{References}

[1] Molden DJ (2007) A comprehensive assessment of water management in agriculture International Irrigation Management Institute, Colombo.

[2] Small, L. E. and Svendsen, M. (1992). A frame works for assessing irrigation performance. Journal of Irrigation and Drainage System, 4. Washington D. C, USA., P 283-312.

[3] Zeleke Agide Dejen (2014). Hydraulic and Operational Performance of Irrigation Schemes in View of Water Saving and Sustainability. Balkema: CRC Press.

[4] Makombe, G., Namara, R., Hagos, F., Awulachew, S. B., Ayana, M. and Bossio, D. (2011). A Comparative Analysis of the Technical Efficiency of Rain-Fed and Smallholder Irrigation in Ethiopia. Colombo, Sri Lanka: International Water Management Institute. pp. 37.
[5] MoWR (2002). Water Sector Development Programme 2002 2016. IrrigationDevelopment Program, Main report. MoWR, Addis Ababa, Ethiopia. pp. 142.

[6] Awulachew, S. B., Teklu, E. and Regassa, E. N. (2010b). Irrigation Potential in Ethiopia; Constraints and Opportunities for Enhancing the System. International Water Management Institute.

[7] WWDSE (Water Works Design and Supervision Enterprise), 2011. Feasibility study of kuraz Sugar development project Report.

[8] Kloezen, W. H. and Garces-Restrepo, C. (1998). Assessing irrigation performance with comparative indicators: the case of Alto Rio Lerma irrigation district, Mexico, research report 22. Journal of IWMI, Colombo, Sri Lanka, accessed on 12/11/2016, http://dlc.dlib.indiana.edu.

[9] Bos, M. G. (1997). Performance indicators for irrigation and drainage. Irrigation and Drainage systems, 11: 119-137.

[10] Bos, M. G., Burton, M. A, and Molden, D. J. (2005). Irrigation and drainage performance Assessment practical guidelines. Journal of Centre for Advanced Biomedical Imaging, 22, Wallingford, UK, p 28-59.

[11] Molden, D. J. And Gates, K. (1990). Measurements of evaluation of irrigation water delivery Systems. Journal of Irrigation and Drainage Engineering, 116 (6), ASCE, $p$ 804823 .

[12] Javaid A. (2005). Improving operational performance and management of canal irrigation System using hydraulic modeling.

[13] Baily, C. and Lenton, R. (1994). A management tool for Gezira irrigation system. In conference procedig about "water distribution in Sudan agriculture productivity and equity", University of Gezira, Wad Medani, Sudan, p 59-68.

[14] Rao, P. S. 1993. Review of selected literature on indicators of irrigation performance. International Irrigation Management Institute. IIMI Publications. Colombo, Sri Lanka.

[15] Binoy, M. A., Varghese, S., and Paul, K. (2013). Paul Irrigation system assessment farmers and managers view. International Journal of Engineering Science and Innovative Technology (IJESIT), 2, Issue 2, Kothamangalam, Indian, $p$ 148-159.

[16] Howell, T. A. (2001). Enhancing water use efficiency in irrigated agriculture. Jornal of Agron. J, p 281-289.

[17] Mohsen, A., Kiamura, Y. And Shimizu, K. (2012). Assessment of irrigation practices at main irrigation network in the Nile Delta. International Jornal of Biolgical, Veterinary, Agricultural and Food Enginnering, 16 (9), World Academy of Science, Engineering and Technology, p 1-8.

[18] Ucar, Y, Senyigit, U, Kadayifci, A, and Tuylu, GI. 2010. Evaluation of water use efficiency at parcel and scheme levels: a case study of Sarkikaraagac irrigation scheme in Turkey. Journal of Food, Agriculture and Environment 8 (2): $1046-1053$

[19] Bos, M. G., Murray-Rust, D. H., Merry, D. J., Johnson, H. G. and Snellen, W. B. (1993). Methodologies for assessing performance of irrigation and drainage managment, The Netherlands. 
[20] Shafique, M. S. (1993). Performance of the Gezira canals. An internal review program. International Irrigation Management Institute, Sudan, Colombo, Sir Lanka'.

[21] D. Clarke. CROPWAT version 4.2 for Windows, users'guideline, University of Southampton, UK, 1998.

[22] Aksara, P. \& Pasin, S. (2015). Water requirements and irrigation scheduling of ban khai Irrigation project using GIS and CropWat model in rayong province Thailand.

[23] Raghava, S., Venkateswarao, B., and Sreekanth, S. (2011). Modernization of an existing. irrigation project by performance evaluation using performance indicators, India. International Journal of Mathematics and Engineering, 141, p, 1273-1292. 